(6)

OPEN ACCESS

\title{
Penetrating paediatric neck trauma
}

\author{
Monica Abdelmasih, ${ }^{1}$ Ahmed Kayssi, ${ }^{2}$ Graham Roche-Nagle ${ }^{\circledR}$
}

'Division of Vascular Surgery, University of Toronto, Toronto, Ontario, Canada

${ }^{2}$ Division of Vascular Surgery, Sunnybrook Health Sciences Centre, Toronto, Ontario, Canada

${ }^{3}$ Division of Vascular Surgery, Toronto General Hospital, Toronto, Ontario, Canada

\section{Correspondence to}

Dr Graham Roche-Nagle, graham.roche-nagle@uhn.ca

Accepted 29 January 2019

\section{SUMMARY}

Penetrating injuries to the internal carotid artery are infrequent but potentially devastating and can be a significant challenge to the operating surgeon. In this article, we present a case of an 11-year-old girl who suffered a serious vascular injury when she fell on a pencil. We also discuss the most up-to-date recommendations concerning the management of zone II injuries to the neck of a paediatric patient.

\section{BACKGROUND}

Penetrating neck injuries are uncommon in children, ${ }^{1}$ and management traditionally involves mandatory exploration of the neck. Mandatory exploration of the neck in children should not be performed unless clinically indicated. Preoperative imaging should be used routinely to reduce unwarranted surgical explorations, improve diagnostic accuracy and lower morbidity.

\section{CASE PRESENTATION}

An 11-year-old girl was transferred to The Hospital for Sick Children in Toronto, Ontario, from a regional health centre with a penetrating neck

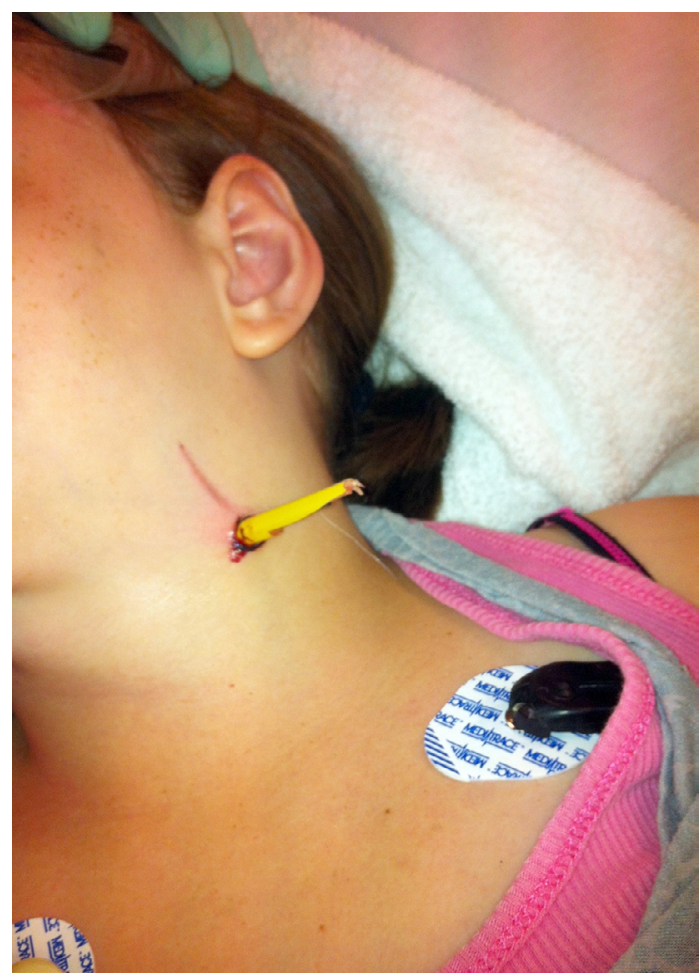

Figure 1 Initial presentation with the pencil protruding from the left neck.

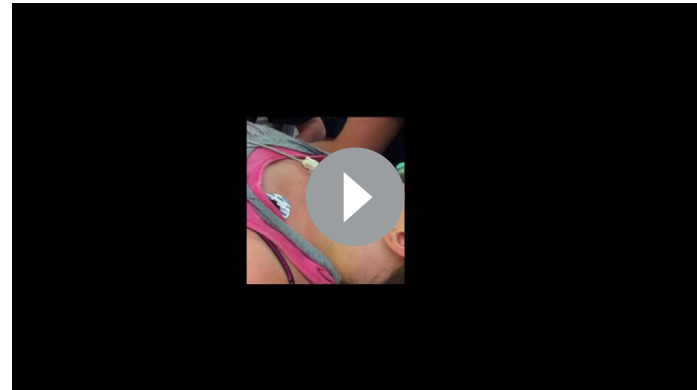

Video 1 Initial presentation with the pencil protruding from the left neck and pulsating.

injury. During recess at her school, she fell and lodged the sharpened end of a pencil into the left side of her neck. She was urgently transported by ambulance with the pencil kept in place.

\section{INVESTIGATIONS}

On initial examination, there was a pencil protruding from the left side of the neck with no external bleeding or haematoma from the puncture site (figure 1, video 1). Her initial vital signs were within normal range and there was no evidence of respiratory distress or stridor. As she was stable and we wanted to define her anatomy prior to proceeding to the operating room, a neck $\mathrm{CT}$ angiogram (CTA) was obtained. This demonstrated that the pencil was lodged in her left common carotid artery (CCA) causing total occlusion (figure 2). The remainder of her neck was unremarkable.

\section{TREATMENT}

The patient was taken to the operating room for left neck exploration. A first-generation cephalosporin was administered perioperatively. Using vessel loops, we gained control of the common carotid, internal carotid and external carotid artery (ECA) and then exposed the pencil (figure 3). She received a weight-based therapeutic dose of heparin, the arteries were clamped and the pencil was removed (Video 2). The arterial edges were refreshed and an end-to-end anastomosis was performed under no tension using 7-0 prolene sutures. The wound was irrigated with copious amounts of sterile saline then closed in layers with vicryl and nylon sutures. No drains were placed.

\section{OUTCOME AND FOLLOW-UP}

After an uneventful recovery in the hospital, the patient was discharged home on the second postoperative day. She was initiated on acetylsalicylic acid for 3 months following surgery. The wound 

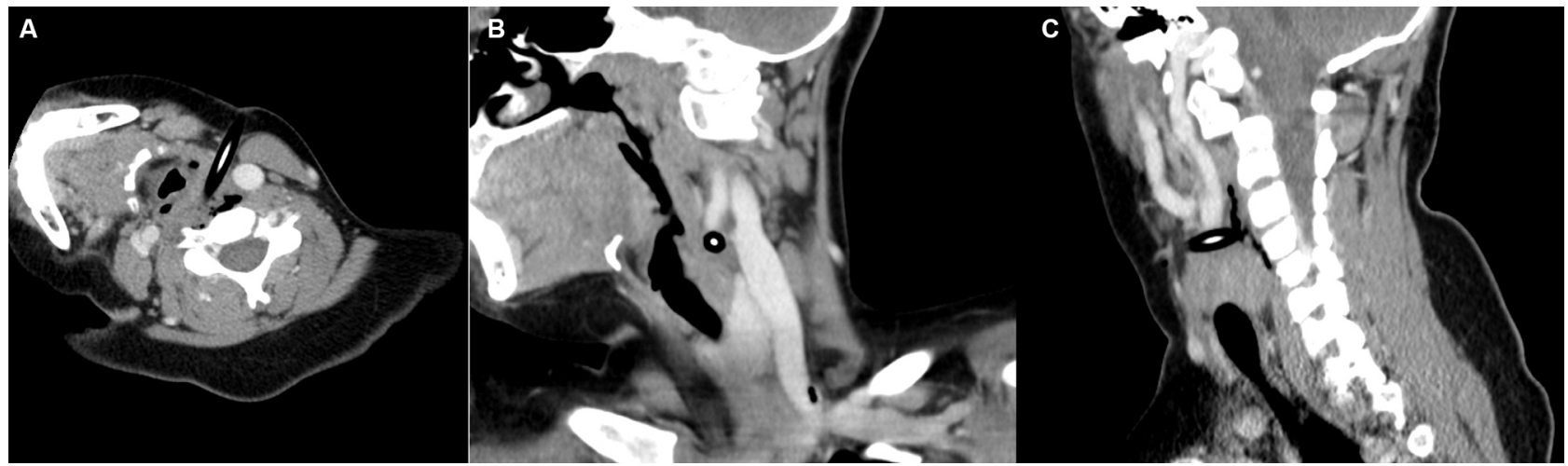

Figure $2 \mathrm{CT}$ angiogram images demonstrating the pencil lodged in the left common carotid artery resulting in total occlusion as seen in the axial (A), coronal (B) and sagittal (C) views.

had healed well at follow-up. She underwent monitoring with duplex ultrasound at 6 weeks then every 6 months for 1 year then yearly for 2 years. Ultrasound 3 years later demonstrated no abnormalities.

\section{DISCUSSION}

Penetrating neck injuries refer to neck injuries that breach the platysma muscle. This can result from gunshot wounds, stab wounds or penetrating debris, such as glass or shrapnel. These injuries can cause harm to the airway, digestive and neurovascular systems. While penetrating neck injuries in children are uncommon ${ }^{1}$ in comparison to adults, these injuries may be more devastating due to their smaller anatomy ${ }^{2}$; thus, additional structures can be damaged by the penetrating object. For this reason, it is important to competently evaluate and manage a child with penetrating neck trauma. Furthermore, it is equally important not to remove a penetrating object unless under direct surgical visualisation with the appropriate resources.

A paper by Stone et al described paediatric penetrating trauma between 2008 and 2012 from the National Trauma Data Bank (NTDB). ${ }^{3}$ A total of 1238 patients with penetrating neck trauma were identified among 434788 children in the NTDB (0.28\%). Mean age was 7.9 years, and $70.6 \%$ of patients were male. The most common mechanisms of injury were stabbing (44\%) and gunshot/firearm (24\%). CT scan was the most frequent diagnostic study performed (42.2\%), followed by laryngoscopy (27.0\%) and oesophagoscopy (27.4\%). There were 69 deaths,

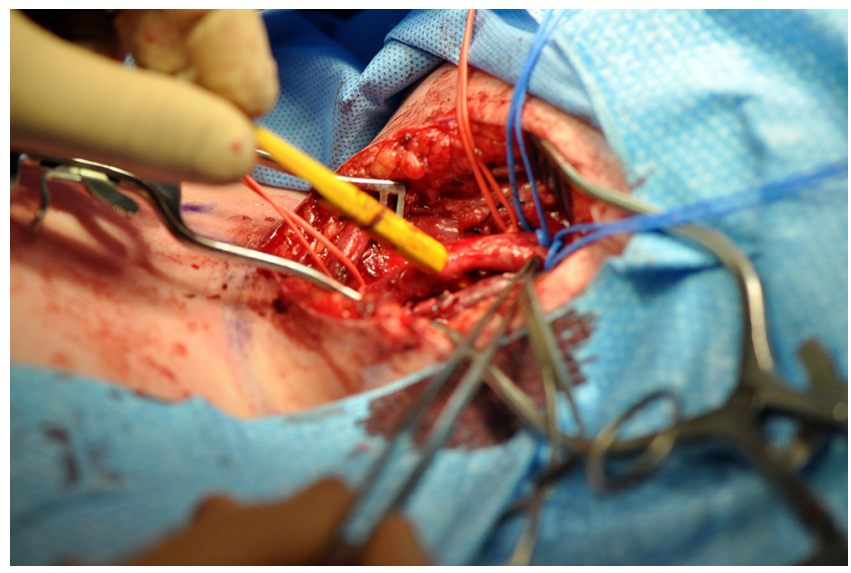

Figure 3 Neck exploration showing control of the left common carotid artery, internal carotid artery and external carotid artery with the pencil clearly dissected. yielding a mortality rate of 5.6\%. After adjusting for age, admission to a paediatric trauma centre and injury type, only vascular injury (OR 3.92; 95\% CI 2.19 to $7.24 ; \mathrm{p}<0.0001$ ) and emergency department hypotension (OR 27.12; 95\% CI 15.11 to $48.67 ; \mathrm{p}<0.0001)$ were found to be independently associated with death.

A small subset of reports has further categorised paediatric vascular injuries based on the carotid vessel involved. Corneille et al performed a retrospective review between 1995 and 2008 identifying 116 paediatric patients with 111 arterial injuries. ${ }^{1}$ They reported in surviving patients with head and neck vascular injuries, four suffered penetrating trauma and three had blunt trauma, resulting in four CCA injuries and three internal carotid artery (ICA) injuries. For patients with CCA injuries, two underwent primary repair, one underwent venous interposition grafting and one had a vein patch. Of the ICA injuries, all three did not undergo vascular repair. There was one non-surviving patient with a penetrating ICA injury. Allen et al published their findings from a level I trauma centre looking at 103 paediatric patients with major vascular injuries over a 12 -year period. ${ }^{4}$ Blunt injuries accounted for $42 \%$ whereas penetrating injuries occurred in $58 \%$ of patients. CCA and ICA injuries were identified in six and three patients, respectively. Of the CCA injuries, four were managed non-operatively, one underwent primary repair and one underwent synthetic grafting. Of the ICA injuries, two were managed

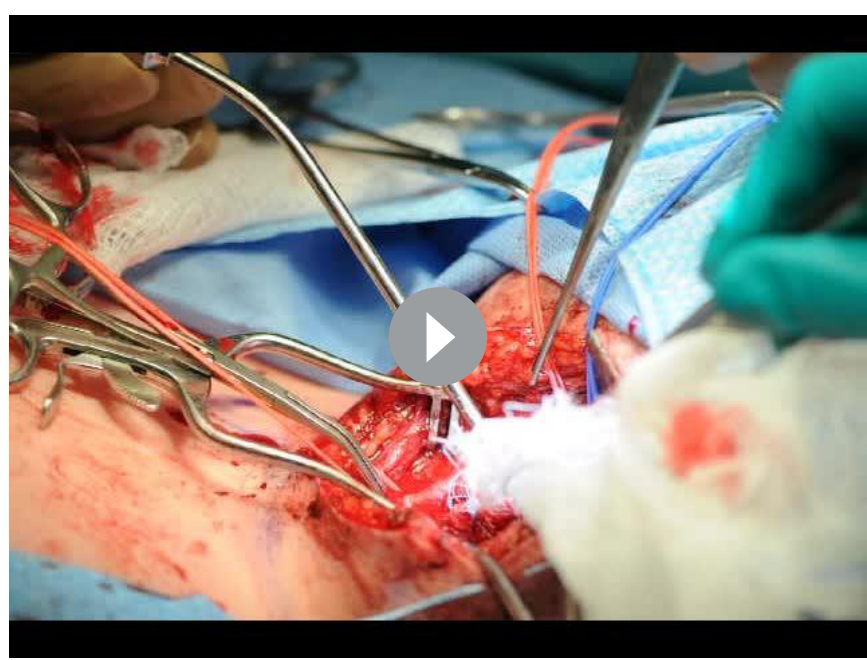

Video 2 Intraoperative removal of the pencil from the left common carotid artery showing the intact edges of the vessel which were refreshed prior to primary repair. 
non-operatively and one underwent primary repair. There was one ECA injury for which primary repair was performed. As expected, more patients with penetrating trauma required operative repair in this study than those with blunt trauma.

Children frequently use pens and pencils and there have been a number of publications concentrating on these tools as an instrument of injury. Hewett and Mellick described a case of a 9-year-old girl who fell while carrying a pencil and suffered a penetrating injury to zone II. $^{5}$ She was stable on arrival to the emergency department and exhibited no hard signs of injury. A CTA showed that the pencil was positioned between her carotid artery and jugular vein without damaging either of these vessels. She was taken to the operating room where the pencil was removed and was discharged 2 days later. In a case series by Fisher et al, 14 children were identified between 2005 and 2009 as having penetrating trauma caused by pens or pencils. ${ }^{6}$ These events were more common in males (64\%) with $21 \%$ of injuries occurring at school. Other easily available household items have also been implicated in such injuries. Clothing hangers accounted for 394 head and neck injuries between 2002 and 2012 in a report by Walls et al..$^{7}$ The majority of children injured, however, were not admitted to hospital. A case of penetrating oropharyngeal trauma reaching the parapharyngeal space beyond the carotid vessels has been reported even with a typically benign item, such as a toothbrush. ${ }^{8}$

The neck is divided into three anatomical zones. Zone I extends from the clavicle to the cricoid cartilage, zone II from the cricoid cartilage to the angle of the mandible and zone III from the angle of the mandible to the base of the skull. Zone II injuries have been shown to be the most common. ${ }^{9-12}$ The management of zone II neck injuries has evolved numerous times during the 20th century. Before World War II, all penetrating neck trauma was treated using a watch and wait approach, resulting in mortality rates as high as $35 \% .{ }^{13}$ In response to this high mortality rate, mandatory exploration was advised for any injury penetrating the platysma muscle. Despite the fact that this methodology reduced the mortality rate, there was a relatively high rate of negative neck explorations. ${ }^{9}{ }^{10}$ Recent trauma guidelines on the management of penetrating zone II adult neck trauma propose avoiding mandatory neck exploration of zone II injuries toward expectant and selective operative management with greater use of CT imaging-based assessment to prevent unnecessary operative morbidity. ${ }^{14}$

As a result, a similar approach has been proposed in the paediatric population, with selective exploration based on clinical signs and radiological findings. ${ }^{15-17}$ This practice of selective management of penetrating neck injuries based on physical examination and selective use of investigations appeared safe with a low negative exploration rate and no missed injuries. Moreover, a high rate of negative neck explorations has been reported in the paediatric literature when management is based solely on penetration of the platysma or zone II involvement. ${ }^{10-12}$ In our case, although there were no hard signs of injury on clinical examination, the CT scan demonstrated penetration of the carotid artery by the pencil mandating surgical exploration and repair of the vascular injury.

In conclusion, penetrating neck trauma in children is a rare yet serious presentation in paediatric emergency departments. Management of penetrating neck trauma in children includes selective neck exploration based on physical examination and the use of CTA in stable patients, similar to current adult recommendations.
Learning points

- Penetrating neck injuries in children are uncommon but may result in significant morbidity and mortality.

- A penetrating object should never be removed at the scene and should only be removed under direct surgical visualisation.

- Emergent neck exploration is required for patients presenting with penetrating cervical trauma and hard signs of vascular injury or airway compromise.

- In stable paediatric patients with no hard signs of injury or airway compromise, selective neck exploration should be employed based on physical examination and further imaging modalities.

Contributors MA, GR-N and AK contributed to the drafting and revising of this work and final approval of the version published.

Funding The authors have not declared a specific grant for this research from any funding agency in the public, commercial or not-for-profit sectors.

Competing interests None declared.

Patient consent for publication Obtained.

Provenance and peer review Not commissioned; externally peer reviewed.

Open access This is an open access article distributed in accordance with the Creative Commons Attribution Non Commercial (CC BY-NC 4.0) license, which permits others to distribute, remix, adapt, build upon this work non-commercially, and license their derivative works on different terms, provided the original work is properly cited and the use is non-commercial. See: http://creativecommons.org/ licenses/by-nc/4.0/

\section{REFERENCES}

1 Corneille MG, Gallup TM, Villa C, et al. Pediatric vascular injuries: acute management and early outcomes. J Trauma 2011;70:823-8.

2 Hanson CA, Smith JA. Penetrating neck injuries in children. J Trauma Nurs 2007:14:12-16.

3 Stone $\mathrm{ME}$, Farber $\mathrm{BA}$, Olorunfemi $\mathrm{O}$, et al. Penetrating neck trauma in children: An uncommon entity described using the national trauma data bank. J Trauma Acute Care Surg 2016;80:604-9.

4 Allen CJ, Straker RJ, Tashiro J, et al. Pediatric vascular injury: experience of a level 1 trauma center. J Surg Res 2015;196:1-7.

5 Hewett KM, Mellick L. A case of penetrating neck trauma in a child. Pediatr Emerg Care 2012;28:49-51.

6 Fisher SB, Clifton MS, Bhatia AM. Pencils and pens: an under-recognized source of penetrating injuries in children. Am Surg 2011;77:1076-80.

7 Walls $A$, Pierce M, Wang $\mathrm{H}$, et al. Clothing hanger injuries: pediatric head and neck traumas in the United States, 2002-2012. Otolaryngol Head Neck Surg 2014;150:300-4

8 Sagar S, Kumar N, Singhal M, et al. A rare case of life-threatening penetrating oropharyngeal trauma caused by toothbrush in a child. I Indian Soc Pedod Prev Dent 2010;28:134-6.

9 Kim MK, Buckman R, Szeremeta W. Penetrating neck trauma in children: an urban hospital's experience. Otolaryngol Head Neck Surg 2000;123:439-43.

10 Mutabagani KH, Beaver BL, Cooney DR, et al. Penetrating neck trauma in children: a reappraisal. J Pediatr Surg 1995;30:341-4.

11 Vick LR, Islam S. Adding insult to injury: neck exploration for penetrating pediatric neck trauma. Am Surg 2008;74:1104-6.

12 Abujamra L, Joseph MM. Penetrating neck injuries in children: a retrospective review. Pediatr Emerg Care 2003;19:308-13.

13 Thal ER, Meyer DM, trauma PneckCurr Prob/ Surg 1992;29:5-56.

14 Sperry JL, Moore EE, Coimbra R, et al. Western trauma association critical decisions in trauma: penetrating neck trauma. J Trauma Acute Care Surg 2013;75:936-40.

15 Tessler RA, Nguyen $\mathrm{H}$, Newton C, et al. Pediatric penetrating neck trauma: Hard signs of injury and selective neck exploration. J Trauma Acute Care Surg 2017;82:989-94.

16 Prichayudh S, Choadrachata-anun J, Sriussadaporn S, et al. Selective management of penetrating neck injuries using "no zone" approach. Injury 2015;46:1720-5.

17 Cooper A, Barlow B, Niemirska M, et al. Fifteen years' experience with penetrating trauma to the head and neck in children. J Pediatr Surg 1987;22:24-7. 
Copyright 2019 BMJ Publishing Group. All rights reserved. For permission to reuse any of this content visit https://www.bmj.com/company/products-services/rights-and-licensing/permissions/

BMJ Case Report Fellows may re-use this article for personal use and teaching without any further permission.

Become a Fellow of BMJ Case Reports today and you can:

- Submit as many cases as you like

- Enjoy fast sympathetic peer review and rapid publication of accepted articles

Access all the published articles

- Re-use any of the published material for personal use and teaching without further permission

For information on Institutional Fellowships contact consortiasales@bmjgroup.com

Visit casereports.bmj.com for more articles like this and to become a Fellow 